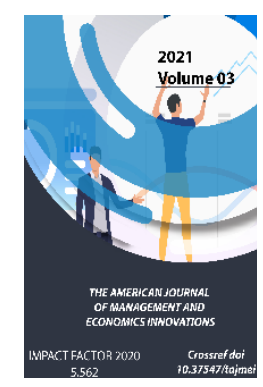

\title{
The Mechanism Of Interaction Of Priorities Of Food Provision And Strategies For The Development Of The Agro- Industrial Complex
}

Khumoyun Kh. Egamberdiev

Doctoral Student, National University After Named Mirzo Ulugbek, Uzbekistan

Journal Website: https://theamericanjou rnals.com/index.php/ta jmei

Copyright: Original content from this work may be used under the terms of the creative commons attributes 4.0 licence.

\section{ABSTRACT}

The article considers the mechanism of interaction of priorities of food provision and strategies for the development of the agro-industrial complex. The notion "imported food" as well as positive and negative consequences of this policy impact on the national economy, as a whole. Herewith, it considers the interrelation between pursuing the policy of import substitution in agriculture and food safety of regions. The author considers the essence of the notion "food provision", as well as questions and criteria related to ensuring food safety on the level of the region. When defining the basic goals of the import substitution policy to ensure food safety, the author analyze the areas of improving the doctrine of food safety used within the import substitution policy to ensure food safety of the country.

\section{KEYWORDS}

Food Provision, Imported Food, Agro-Industrial Complex, Food Security, Agricultural Sector.

\section{INTRODUCTION}

Rural areas and the agricultural sector are currently experiencing a radically new social and economic situation which barely fits the existing national agricultural policy as a longterm instrument for stimulating the agri-food market and government's support of the agrarian sector and, primarily, agriculture that underlies it. In the age of globalization of national agri-food markets, food supply security based on import substitution can be ensured in a macro-economic environment that favors the development of a competitive agricultural industry. 
In the course of human history, the provision of food to the population has been one of the most crucial government tasks. The country's food security is an integral part of its national security. Improving the provision of highquality food to the population is an essential socio-economic task, the solution of which is of great importance for Uzbekistan.

\section{THE MAIN RESULTS AND FINDINGS}

Food security is a complex concept containing at least two significations. The first is related to the purely economic process of food provision. The second is caused by the importance of food security to maintain national security in its internal and external manifestations.

From theoretical and methodological positions, it is necessary to make some clarifications to a number of concepts that are of fundamental importance in the development of an effective agri-food policy in the formation of a sustainable food security system at different territorial levels.

In the scientific publications, this concept of "food security" is interpreted in several ways. Thus, the food security of Uzbekistan and its regions is understood as "such a guaranteed level of quantitative and qualitative provision of food available to all, in which the maximum possible average life expectancy of people in modern conditions is achieved" [1].

Many authors consider the concept of food security as well as the ability of the state to guarantee the satisfaction of the needs of the population of the country for food at a level that ensures its normal functioning. At the same time, an important condition for the country's food security is the satisfaction of the main part of the food needs at the expense of domestic production. This vital function is carried out by the agro-industrial complex (AIC).

The food security of the regions is based "on a rational division of labor in the field of agricultural production, a rational combination in the consumption of local and imported products, the absence of any barriers to interregional food trade" [2].

The reliability of the state's food security is determined by a number of indicators, the most essential of which are the following:

$>$ The level of agricultural production of the country; the degree of self-sufficiency in food; the availability of rolling stocks; the level of consumption of critical products and the degree of availability of food for the poorest part of the population and the size of this group;

$>$ In general, the food security of our country consists of the level of food self-sufficiency of each of its regions, if we approach this problem not only from the standpoint of stable self-sufficiency in agricultural products, raw materials and food, but also from the employment of the rural population. After all, it is possible to solve the problem of agri-food products through its import, especially since initially, until the complete cessation of domestic agricultural production, prices for it will be lower than prices for food produced in the country. Such a situation is quite possible in the case, for example, of a country's accession to the WTO.

Naturally, such a variant of the country's food provision is not admissible, since it does not meet the interests of its security - not only food, but also economic. However, this raises a number of questions that require explanation: 
1. If the country's food security system consists of the volume of production of agricultural products, raw materials and food in the regions as subjects of the republic and collectively constituting a single whole - the country, then is there a problem of food security of a single region (or several regions), or should we talk only about their self-sufficiency?

2. At what proportion of regions in the country that are unable to self-sustain themselves with the major types of agri-food products produced in them, we can discuss the following problems:

$>$ The critical level of food security of the state as a whole or only its individual regions;

$>$ Food security at the regional level;

$>$ Food security and food independence of the country.

3. Who exactly at the state level is responsible for observing the acceptable level of food security of an individual in each region?

4. At what proportion of regions that are unable to ensure food independence, that is, incapable of bringing food selfsufficiency in basic foodstuffs to a normative level, can we assert the critical importance of food dependence of the country as a whole?

5. In determining the level of food independence of a country, should we proceed from the optimal value of food dependence, taking into account the expansion of world economic relations, in the whole country, or from the maximum level of self-sufficiency of most of its regions?
6. Is it possible to consider the country's food security achieved if it is provided only for a short period of time, for example, for one year, or is it necessary to take into account several years?

In connection with the abovementioned, the following definition could be given: "The food supply of the region is a process of sustainable satisfaction of the population in food products within the framework of scientifically-based medical standards, taking into account its gender and age groups and effective demand on the basis of more efficient use of the resources of the food subcomplex and the use of a competitive food wholesale and retail system that meets its interests, capable of optimizing the distribution of regional and imported food in large cities, industrial centers and individual territorial formations, as well as ensuring its implementation at affordable prices for the majority of the population with an optimal share of imports." The concept of "imported food" includes food products imported to the region not only from far and near abroad, but also from other regions of the country within the framework of existing trade relations.

At the same time, the regulatory role of the state here should be manifested, in our opinion, in the organization of a more purposeful distribution of imported food flows to domestic regions, using legislative and legal levers and a motivational mechanism corresponding to the interests of the region. For instance, in the northern territories, where the level of food self-sufficiency is low and agricultural production is high-cost, food is imported from far and near abroad. It should be noted that the employment of the rural population in such regions is carried out on the 
basis of the development of diversified agricultural entrepreneurship, as well as through the production of agricultural products in private subsidiary farms. The missing agro-food products in other, nonnorthern territorial formations are imported from other regions of Uzbekistan. The question remains open, how much agricultural products to produce in the regions and how much to import is a serious socio-economic problem. It affects the interests of the state, entrepreneurship and the population of the regions associated with increasing rural employment based on the development of agricultural production, preserving the rural lifestyle and the multifunctional role of agriculture, strengthening the country's food independence.

In the available literary sources, several variants of the approach to determining the level of food security related to food security and food independence are proposed. Thus, in one source, an attempt is made to solve the problem based on mathematical modeling, based on the production of the main types of agricultural products necessary to meet the average per capita needs at the level of the consumer basket, taking into account such factors as the level of state financial support for agriculture, the volume of imported food, the size of household incomes, the level of environmental pollution of agricultural products [3].

In another, the state of food security is assessed by such indicators as the sufficiency of minimum costs, pensions and benefits for access of socially vulnerable groups to food at the level of established norms, the minimum required volume of production of agri-food products, the size of transitional and strategic food stocks for two levels (sufficient and minimum necessary), as well as the real volume and quality of nutrition in the context of these levels. Thirdly, a "multifactorial influence on the economic availability of food (according to 25 indicators) is given based on a comparison of per capita income of the population and retail prices" [4]. At the same time, the level of economic availability of food can be determined taking into account the volume and structure of food purchases by different categories of the population, with the addition of such indicators as the volume of imported and exported food, the size of state food funds and reserves, as well as the volume of food for national needs.

An attempt at an integrated approach to assessing the possibilities of food selfsufficiency in the region was first made by $\mathrm{V}$. Maslakov. However, even in this methodological approach, there is no connection between the assessment and the development opportunities of the regional agro-industrial complex, and especially its agricultural sector, which is the basis for creating a sustainable regional food supply system. At the same time, it is taken into account that the priority development of the agricultural sector directly consists of a set of strategies and tasks of each agricultural enterprise in the region. In this regard, the following definition could be proposed: "The priority development of an organization agro-enterprise) is, firstly, the choice and justification of its mission, the main and related goals of socio-economic development; secondly, it is the development of a mechanism (algorithm) for solving problems that ensure the choice of the optimal option for achieving the main and related tasks with minimal resource consumption and overcoming various 
kinds of risks; thirdly, it is a mechanism for achieving competitive advantages in the market, provided that the rational interaction of the enterprise with the surrounding market and environmental environments is ensured."

An essential stage is the selection of tasks, the solution of which in a logical sequence will ensure the processes of optimizing the choice of a rational option for achieving the main and related goals. Moreover, the optimality of the resulting development option, obtained with minimal expenditure of resources, should be adjusted to minimize the cumulative risk. As for specific advantages, the mechanism for achieving them is very complex, since it is necessary to take into account not only the relevant antitrust legislation, which is related to the market environment, but also violation of requirements that can be prosecuted in accordance with the law.

\section{CONCLUSION}

Therefore, the enterprise's desire to achieve competitive advantages in the market should take place on condition of ensuring the harmonization of relations with the business environment, the population of the territories and the state. This conclusion is typical for the agro-industrial complex as a whole. However, the implementation of the selected priorities will require an appropriate management mechanism.

\section{REFERENCES}

1. Vartanova M. L. Food security of the country and the ways out of the global food crisis: monograph /Vartanova $M$. L. - Moscow : Biblio-Globus, 2016.

2. Kostyaev A. I., Timofeev, M. W. National and regional food security //SB. scientific works of the
International jubilee conference. Moscow : RASKHN, UNITECH, 2000. S. 500.

3. Ezersky, E. N., Pavlova, S. N., Drokin, V. V., Postweb, A. L. Formation of a regional system of food security. Yekaterinburg: UrGSHA, 2004.

4. Altukhov, A. I. Methodology for determining the level of food security of the country // Agroindustrial complex : economics, management. 2006. No. 8. p. 2. 